was evaluated, using erythrocyte sedimentation rate (ESR) as a reference. Disease activity assessment models were constructed and concordance index (C-index), net reclassification index (NRI), and integrated discrimination index (IDI) were evaluated to compare the benefits of the new modes with ESR and Kerr score.

Results: In total, 64 (70.3\%) cases showed active disease. Higher levels of ESR and CRP, and lower interleukin (IL)-2R levels, were observed in active cases. 18F-FDG-PET/CT parameters, including SUVmean, SUVratio1, SUVratio2, sum of SUVmean, and sum of SUVmax, were significantly higher in active disease groups. The $\mathrm{C}$ index threshold of ESR to indicate active disease was 0.78 (95\% Cl: 0.69-0.88). The new activity assessment model combining ESR, sum of SUVmean, and IL-2R showed significant improvement in $C$ index over the ESR method (0.96 vs. $0.78, P<0.01$; NRI 1.63, $\mathrm{P}<0.01$; and IDI $0.48, P<0.01)$. The new model also demonstrated modest superiority to Kerr score assessment $(0.96$ vs. $0.87, \mathrm{P}=0.03$; NRI $1.19, \mathrm{P}<0.01$; and IDI $0.33 \mathrm{P}<0.01$ )

Conclusion: A novel 18F-FDG-PET/CT-based method that involves combining the sum of SUVmean with ESR score and IL-2R levels demonstrated superiority in identifying active TA compared to conventional methods.

REFERENCES:

[1] Kerr GS, Hallahan CW, Giordano J, Leavitt RY, Fauci AS, Rottem M, et al. Takayasu arteritis. Ann Intern Med 1994;120:919-29.

[2] Hoffman GS, Ahmed AE. Surrogate markers of disease activity in patients with Takayasu arteritis. A preliminary report from The International Network for the Study of the Systemic Vasculitides (INSSYS). Int J Cardiol 1998;66 Suppl 1:S191-4; discussion S195.

[3] Misra R, Danda D, Rajappa SM, Ghosh A, Gupta R, Mahendranath KM, et al. Development and initial validation of the Indian Takayasu Clinical Activity Score (ITAS2010). Rheumatology (Oxford) 2013;52:1795-801.

[4] Bardi M, Diamantopoulos AP. EULAR recommendations for the use of imaging in large vessel vasculitis in clinical practice summary. Radiol Med 2019;124:965-972.

[5] Spick C, Herrmann K, Czernin J. 18F-FDG PET/CT and PET/MRI Perform Equally Well in Cancer: Evidence from Studies on More Than 2,300 Patients. J Nucl Med 2016;57:420-30.

Disclosure of Interests: None declared

DOI: 10.1136/annrheumdis-2021-eular.3739

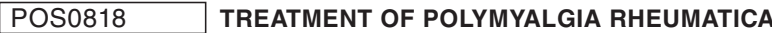 WITH TOCILIZUMAB: RESULTS OF AN OBSERVATIONAL RETROSPECTIVE MULTICENTER STUDY}

M. Assaraf ${ }^{1}$, B. Chevet $^{2}$, P. Philippe ${ }^{1}$, J. Avouac $^{3}$, M. Delacour ${ }^{4}$ E. Houvenagel ${ }^{5}$, T. Pascart ${ }^{5}$, J. Henry ${ }^{6}$, C. Roux ${ }^{7}$, D. Wendling ${ }^{8}$, J. Paccou', B. Cortet ${ }^{1}$, V. Devauchelle-Pensec ${ }^{2}$, R. M. Flipo' ${ }^{1}{ }^{1}$ Lille University Hospital, Rheumatology, Lille, France; ${ }^{2}$ Brest University Hospital, Rheumatology, Brest France; ${ }^{3}$ Cochin University Hospital, Rheumatology, Paris, France; ${ }^{4}$ Arras Hospital Medical Center, Rheumatology, Arras, France; ${ }^{5}$ Saint Philibert University Hospital, Rheumatology, Lomme, France; ${ }^{6}$ Kremlin Bicêtre Univeristy Hospital, Rheumatology, Paris, France; ${ }^{7}$ Nice University Hospital, Rheumatology, Nice, France; ${ }^{8}$ Besançon University Hospital, Rheumatology, Besançon, France

Background: In 2017, TOCILIZUMAB (TCZ) obtained marketing authorization for treatment of giant cell arteritis (GCA); however, this doesn't extend to polymyalgia rheumatica (PMR) therapy. Based on efficacy data for TCZ in GCA, TCZ is sometimes used as a glucocorticoid (GC) sparing agent when PMR is $\mathrm{GC}$ dependent or when a rapid steroid withdraw is needed. Currently, there are no available recommendations on the use of this therapeutic class in for this particular indication.

Objectives: Here, we present the results of an observational French multicentric study of patients with PMR treated with TCZ.

Methods: Thirteen medical centers were included in this study. The data was collected retrospectively between 2015 and 2020. The minimum duration of treatment was 3 months. Patients were included when receiving TCZ for isolated PMR or associated with a non-active GCA (asymptomatic, no vascular fixation on PET scanner).

Results: Overall, 34 patients were included (24 women; mean age 70.1 years $(+/-10.3))$. At TCZ introduction, patients had been treated with GC for a mean duration of 27,9 months $(+/-25.9)$ and the mean GC dose was $16,8 \mathrm{mg} / \mathrm{d}(+/-10)$. Fifteen patients (44\%) had one or more complications from GC therapy. Another immunosuppressant was added before TCZ treatment for $25(74 \%)$; mostly METHOTREXATE $(24 / 25)$
TCZ was initiated intravenously at $8 \mathrm{mg} / \mathrm{kg}$ every 4 weeks for 27 patients (79\%) and subcutaneously at $162 \mathrm{mg} /$ week for 7 patients $(21 \%)$.

The reasons for TCZ introduction included GC dependence $(n=30,88 \%)$, and necessity of quick $\mathrm{GC}$ sparing ( $\mathrm{n}=4$ patients, $12 \%$ ).

Of all patients, $76 \%$ (26 patients) had stopped GC treatment definitively, with a mean time of 9,4 (0-32) months.

The mean TCZ treatment period was 19,2 months (3-66). Fifteen patients (44\%) permanently stopped TCZ at the end of the observation period ( 8 prolonged remissions; 1 myocardial infarction; 1 cutaneous lymphoma; 1 primary failure, 3 lost to follow up).

Eighteen patients (60\%) benefited from an attempted tapering of TCZ (infusion spacing or dose reduction), 6 attempts (1/3) led to a relapse. 1/2 patients had side effects mostly benign (cytopenia $n=6$, infections $n=5$ ).

Conclusion: This is the largest cohort presenting results of the use of TCZ in PMR. Despite the small number of participants, our study suggests TCZ is effective as a GC sparing agent in PMR. As there are no official recommendations of use, indications for TCZ use within this population are no defined. Randomized Controlled Trial would be beneficial to validate these first results.

REFERENCES:

[1] Toussirot, «Biothérapies, pseudo- polyarthrite rhizomélique et artérite à cellules géantes État des lieux en 2018 ».

[2] Devauchelle-Pensec et al., " Efficacy of First-Line Tocilizumab Therapy in Early Polymyalgia Rheumatica ».

[3] Genovese et al., "Longterm Safety and Efficacy of Tocilizumab in Patients with Rheumatoid Arthritis ».

[4] Stone et al., "Trial of Tocilizumab in Giant-Cell Arteritis ».

Disclosure of Interests: None declared

DOI: 10.1136/annrheumdis-2021-eular.3885

\section{POS0819 $\quad$ EMERGENCE OF DE NOVO MANIFESTATIONS DURING INFLIXIMAB TREATMENT IN BEHÇET} SYNDROME

B. Tukek ${ }^{1}$, S. N. Esatoglu ${ }^{2,3}$, G. Hatemi ${ }^{2,3}$, E. B. Caliskan ${ }^{1}$, Y. Ozyazgan ${ }^{4}$, D. Ucar ${ }^{4}$, Y. Ozguler ${ }^{2,3}$, E. Seyahi ${ }^{2,3}$, M. Melikoglu ${ }^{2,3}$, U. Uygunoglu ${ }^{5}$, A. Siva ${ }^{5}$, Z. Kutlubay ${ }^{6}$, I. Fresko ${ }^{2,3}$, S. Yurdakul ${ }^{2,3}$, H. Yazici ${ }^{2,3}$, V. Hamuryudan ${ }^{2,3}$. ${ }^{1}$ Istanbul University - Cerrahpasa, Cerrahpasa Medical Faculty, Department of Internal Medicine, Istanbul, Turkey; ${ }^{2}$ Istanbul University - Cerrahpasa, Cerrahpasa Medical Faculty, Department of Internal Medicine, Division of Rheumatology, Istanbul, Turkey; ${ }^{3}$ Istanbul University - Cerrahpasa, Cerrahpasa Medical Faculty, Behcet Disease Center, Istanbul, Turkey; ${ }^{4}$ Istanbul University - Cerrahpasa, Cerrahpasa Medical Faculty, Department of Ophthalmology Istanbul, Turkey; ${ }^{5}$ stanbul University - Cerrahpasa, Cerrahpasa Medical Faculty, Department of Neurology, Istanbul, Turkey; ${ }^{6}$ Istanbul University Cerrahpasa, Cerrahpasa Medical Faculty, Department of Dermatology, Istanbul, Turkey

Background: Infliximab (IFX) is increasingly used in the management of severe, relapsing or refractory manifestations of Behçet Syndrome (BS). Emergence of de novo manifestations have been reported during IFX treatment, despite efficacy for the initial manifestation that required IFX use ${ }^{1}$.

Objectives: We aimed to survey a sizeable cohort of BS patients treated with IFX for the development of de novo manifestations during treatment.

Methods: A chart review was conducted to identify all BS patients who were given IFX in our Behçet Disease Research Center between 2004 and 2020. Demographic data, indications for IFX initiation, concomitant drugs, prior treatments, and outcomes were recorded. De novo manifestations were defined as new BS manifestations that had not occurred before IFX treatment.

Results: A total of 252 patients used IFX with the main indications being uveitis in 122 , vascular involvement in 82 , parenchymal central nervous system involvement in 32 , gastrointestinal involvement in 11, arthritis in 10, mucocutaneous involvement in 4, and secondary amyloidosis in 1. Of these patients, $17(6 \%)$ had developed a total of 21 de-novo manifestations during a mean follow-up of $38.4 \pm 92$ (SD) months (Table 1). Vascular involvement was the main indication for IFX in the majority $(n=12 ; 71 \%)$ of these 17 patients followed by eye involvement $(n=3 ; 18 \%)$, central nervous system involvement $(n=1)$, and joint involvement $(n=1)$. Concomitant medications were prednisolone in 14 patients, azathioprine in 6 patients, mycophenolate mofetil, cyclosporine-A and methotrexate in 1 patient each. Thirteen patients $(76 \%)$ were in remission for the main indication when de-novo manifestations emerged In 10 patients IFX treatment was intensified either by increasing the dose to 
$10 \mathrm{mg} / \mathrm{kg}$ (2 patients) or by shortening the infusion intervals to 4 weeks (2 patients) along with the addition of corticosteroids or immunosuppressives. In the remaining 7 patients IFX was switched to another agent (cyclophosphamide in 5 , adalimumab in 1 and anakinra in 1). At the time of this survey $8 / 17$ patients were still on IFX for a mean follow-up of $32.5 \pm 24.6$ (SD) months, with concomitant low dose prednisolone in 5, azathioprine in 3 and mycophenolate mofetil in 3 . In addition to the 7 patients who discontinued IFX at the time of de-novo manifestations, 2 more patients had discontinued IFX due to allergic reactions.

Conclusion: De novo manifestations developed during IFX treatment in $6 \%$ of BS patients, despite efficacy for the initial manifestation. Appearance of de novo manifestations mostly in patients with vascular involvement is noteworthy. Intensification of IFX treatment was efficacious in managing de novo manifestations in more than half of these patients.

REFERENCES:

[1] Hamuryudan V et al. Semin Arthritis Rheum. 2015;45(3):369-73.

Table 1. Distribution of de novo manifestations that have emerged in 17 patients

\begin{tabular}{lc}
\hline De-novo manifestations & $\mathbf{2 1}$ \\
\hline Pulmonary artery aneurysm & 1 \\
Pulmonary artery thrombosis & 2 \\
Coronary artery involvement & 3 \\
Superficial thrombophlebitis & 5 \\
Arthritis & 5 \\
Erythema nodosum & 3 \\
Gastrointestinal involvement & 1 \\
Central nervous system involvement & 1
\end{tabular}

Disclosure of Interests: None declared

DOI: 10.1136/annrheumdis-2021-eular.3887

\section{POS0820 INFLIXIMAB FOR VASCULAR INVOLVEMENT IN BEHÇET SYNDROME}

G. Hatemi ${ }^{1,2}$, B. Tukek ${ }^{3}$, S. N. Esatoglu ${ }^{1,2}$, Y. Ozguler ${ }^{1,2}$, M. Melikoglu ${ }^{1,2}$, E. B. Caliskan ${ }^{3}$, S. Ugurlu ${ }^{1,2}$, I. Fresko ${ }^{1,2}$, S. Yurdakul ${ }^{1,2}$, H. Yazici ${ }^{1,2}$, V. Hamuryudan ${ }^{1,2}$. ${ }^{1} /$ stanbul University - Cerrahpasa, Cerrahpasa Medical Faculty, Department of Internal Medicine, Division of Rheumatology, Istanbul, Turkey; ${ }^{2}$ Istanbul University - Cerrahpasa, Cerrahpasa Medical
Faculty, Behcet Disease Center, Istanbul, Turkey; ${ }^{3}$ Istanbul University Cerrahpasa, Cerrahpasa Medical Faculty, Department of Internal Medicine, Istanbul, Turkey

Background: Vascular involvement is an important cause of morbidity and mortality in patients with Behçet syndrome (BS). TNF inhibitors have been reported to be effective for almost all serious manifestations of BS but data on vascular involvement is still limited.

Objectives: To survey the efficacy and safety of infliximab (IFX) in BS patients with vascular involvement followed in a dedicated tertiary center.

Methods: We reviewed the charts of all BS patients who used IFX and identified those who used this drug for vascular involvement. A standard form was used for extracting data on demographic and clinical features, type of vascular involvement, concomitant immunosuppressives, duration of IFX use, relapses, adverse events and outcome.

Results: 83 patients ( 67 men, 16 women, mean age $39.5 \pm 8.4$ SD years) had used IFX for vascular involvement. The number of patients with each type of vascular involvement as the main indication for IFX, and previous treatment modalities right before IFX are presented in the Table 1. 33 patients had more than 1 type of vascular lesion. Additional organ manifestations were eye involvement in 32 , central nervous system involvement in 4 and gastrointestinal involvement in 3 patients. All but one patient used IFX at a dose of $5 \mathrm{mg} / \mathrm{kg}$ every $6-8$ weeks. All patients used concomitant prednisolone and 51 received pulse methylprednisolone during induction. Other concomitant medications were azathioprine in 21 and mycophenolate mofetil in 4 patients. Outcome of IFX treatment at the end of a mean follow-up of 25.9 months (range 1-103) is tabulated according to arterial and venous involvement (Table 1). Overall, $57 / 83$ (68\%) patients obtained remission with no further relapses and IFX could be stopped in $12(14 \%)$ of them. IFX was discontinued due to adverse events in 15 patients. These were allergic reactions in 8 , tuberculosis, disseminated zona, lung adenocarcinoma, fibromyxoid sarcoma, heart failure, systemic lupus erythematosus, and palmoplantar pustulosis in 1 patient each. Three patients had died. Causes of death were lung adenocarcinoma in one patient and pulmonary hypertension related right heart failure due to pulmonary artery thrombosis in 2 patients.

Conclusion: Infliximab seems to be beneficial in Behçet syndrome patients with vascular involvement, even in those who are refractory to immunosuppressives and corticosteroids. No further relapses occurred in $68 \%$ of the patients, and adverse events leading to discontinuation were observed in $18 \%$.

Disclosure of Interests: None declared

DOI: 10.1136/annrheumdis-2021-eular.3971

Table 1.

\begin{tabular}{|c|c|c|}
\hline & Arterial Involvement $(n=36)$ & Venous Involvement $(n=47)$ \\
\hline Main reason for infliximab use & $\begin{array}{l}\text { Pulmonary artery aneurysm and/or thrombosis, } n=29 \\
\text { Peripheral artery aneurysm, } n=4 \\
\text { Aortic aneurysm, } n=3\end{array}$ & $\begin{array}{l}\text { Vena cava superior and/or inferior thrombosis, } n=5 \\
\text { Lower extremity DVT, } n=24 \\
\text { Budd-Chiari syndrome, } n=4 \\
\text { Intracardiac thrombosis, } n=2 \\
\text { Dural sinus thrombosis, } n=7 \\
\text { Leg ulcer, } n=5 \\
\text { Previous treatment }\end{array}$ \\
\hline First line infliximab & 4 & 13 \\
\hline Corticosteroids & 34 & 38 \\
\hline Cyclophosphamide (CYC) & 25 (15/25 refractory to CYC; $10 / 25$ for maintenance after CYC) & 11 (8/11 refractory to CYC; $3 / 11$ for maintenance after CYC) \\
\hline Interferon-alpha & - & 13 \\
\hline Azathioprine & 21 & 17 \\
\hline Mycophenolate Mofetil & 1 & 2 \\
\hline Cyclosporine A & - & 2 \\
\hline $\begin{array}{l}\text { None due to non-compliance } \\
\text { Outcome }\end{array}$ & 2 & 1 \\
\hline Remission, still on infliximab & 16 & 23 \\
\hline Discontinued due to remission & 4 & 8 \\
\hline Discontinued due to adverse events & 5 & 9 \\
\hline Discontinued due to relapse & 5 & 3 \\
\hline Discontinued due to non-compliance & 5 & 3 \\
\hline Died & 2 ( 1 had previously discontinued due to relapse) & 1 \\
\hline
\end{tabular}

